\title{
Programa de educação permanente em saúde e a praxis profissional: possibilidades e desafios
}

\author{
Continuing health education program and professional praxis: possibilities and challenges \\ Programa de educación para la salud permanente y práxis profesional: posibilidades y \\ desafíos
}

Sheila de Oliveira Gonçalves ${ }^{1 *}$, Maria Cecília de Lozzo Garbelini1, Elaine Rossi Ribeiro1.

\begin{abstract}
RESUMO
Objetivo: Identificar o conhecimento dos profissionais da atenção primária a saúde sobre a Política Nacional de Educação Permanente em Saúde. Métodos: Esta pesquisa é descritiva, quantiqualitativa sequencial. A coleta dos dados foi realizada inicialmente com uma entrevista semiestruturada com os dois gestores de saúde, secretário municipal de saúde e coordenador da atenção básica e posteriormente com aplicação de questionários para setenta e quatro profissionais pertencentes às equipes de saúde e Núcleo Ampliado de Saúde da Família e Atenção Básica. Resultados: Observou-se que os gestores possuem pouco conhecimento sobre Educação Permanente em Saúde, necessitando de ampliação da discussão do tema. Quanto aos profissionais, conhecem a Política de Educação Permanente em Saúde, consideram-na relevante, mas tem dificuldade para conceber a educação para o serviço, entendendo que são parte do processo para a implementação da Educação Permanente, mas consideram que são os gestores os responsáveis pela articulação e execução de todo o processo. Conclusão: $O$ estudo identificou 0 conhecimento dos gestores e dos profissionais da Atenção Primária à sobre a PNEPS e EPS.
\end{abstract}

Palavras-chave: Educação permanente, Saúde, Trabalhadores da saúde.

\begin{abstract}
Objective: To identify the prior knowledge of primary health care professionals on the National Policy on Permanent Education in health. Methods: This research is descriptive, with sequential mixed approach. The collection of data was performed with semi-structured interview with two heath managers, to seventy four professionals belonging to the health teams and Expanded Nucleus of Family Health and Basic Care. Results: The analysis of the interviews observed that the managers have little knowledge about Heath Education, requiring an extension of the professionals know the Policy of Permanent Education in Heath, they consider relevant, but they have difficulty implementing the education for the service, consider that they are part of the education process and they consider that the management are responsible for articulating and executing the entire process. Conclusion: The study identified the prior knowledge of managers and professionals of Primary Health Care about the PNEPS and EPS.
\end{abstract}

Keywords: Continuing education, Health, Health personnel.

\footnotetext{
${ }^{1}$ Faculdades Pequeno Príncipe, Curitiba - PR.

*E-mail: sheilasog@hotmail.com
}

SUBMETIDO EM: 5/2020

ACEITO EM: 6/2020

PUBLICADO EM: 10/2020 


\section{RESUMEN}

Objetivo: Identificar el conocimiento previo de los profesionales de la atención primaria a salud sobre la Política Nacional de Educación Permanente en Salud. Métodos: Esta investigación es descriptiva, con abordaje mixto secuencial. La colecta de los datos fue realizada por medio de una entrevista semiestructurada con los dos gestores de salud, el secretario municipal de salud y el coordinador de la atención básica, y la aplicación de los cuestionarios para setenta y cuatro profesionales pertenecientes a los equipos de salud y Núcleo Ampliado de Salud de la Familia y Atención Básica. Resultados: El análisis de las entrevistas observó que los gestores poseen poco conocimiento sobre la Educación Permanente en Salud, necesitando de ampliación de la discusión del tema. En la evaluación de los cuestionarios observó que los profesionales conocen la política de Educación Permanente en Salud, consideran relevante, pero tienen dificultad para la implementación de la educación para el servicio, consideran que son parte del proceso de educación y consideran que los gestores son responsables de articular y ejecutar todo el proceso. Conclusión: El estudio identificó el conocimiento de gestores y profesionales de Atención Primaria de Salud sobre la PNEPS y EPS. Es imperativo guiar a los equipos en las prerrogativas de PNEPS, a fin de proporcionar el desarrollo de acciones que contemplen el aprendizaje necesario y significativo.

Palabras clave: Educación permanente, Salud, Personal de salud.

\section{INTRODUÇÃO}

Os princípios ideológicos da Educação Permanente começaram a ser desenhados no Brasil bem antes da definição do termo Educação Permanente em Saúde, que deu nome à política em 2004 (BRASIL, 1990).

Davini MC (2009) tem relevante contribuição na elaboração teórica e técnica nesse processo que deu subsídio à instituição da Política Nacional, na mudança de olhar sobre a capacitação dos trabalhadores de saúde, com incorporação do aprendizado ao dia a dia, repensando práticas, posicionando o profissional como centro das relações de produção de conhecimento, aumentando o alcance da prática educativa.

O Pacto pela Saúde, em sua dimensão pela gestão, aponta a educação permanente como impulsionadora da Política Nacional de Educação Permanente em Saúde, como mola propulsora da formação dos profissionais do Sistema Único de Saúde, com articulação e diálogo com entes federais, estaduais e municipais (BRASIL, 2005).

A Educação Permanente em Saúde (EPS) é fundamental na qualificação dos profissionais de saúde, por meio do cotidiano, e torna-se o ato de educar mais próximo de cada realidade (CECCIM RB, 2005). Está fundamentada na educação para o trabalho, e busca preencher as lacunas do cotidiano, complementar os anseios dos trabalhadores, com a discussão coletiva, para fortalecimento das ações de saúde (BRASIL, 2004).

Busca-se a formação de profissionais mais autônomos diante de suas comunidades, com formações que contemplem aspectos objetivos e subjetivos, com um novo olhar sobre o processo de trabalho, em suas diferentes dimensões, com apoio ao cuidado, com abrangência as necessidades coletivas e individuais, com capacidade de acolhimento, em compasso com a gestão dos setores, do controle social, do ensino e da atenção a saúde (CECCIM RB e FEUERWERKER LCM, 2004).

A integração entre o serviço e o espaço científico possibilita ampliação das discussões cotidianas e, para tanto, é importante a participação dos diversos atores envolvidos no processo de mudança, com a possibilidade de ampliar o acesso dos profissionais de saúde as instituições de ensino, e fomentar ações de EPS, nos diversos espaços da atenção à saúde (CECCIM RB, 2005).

A Política Nacional de Educação Permanente em Saúde (PNEPS) é um dos pilares do Sistema Único de Saúde (SUS) e busca caminhos para a integração com os serviços de saúde e o saber científico, possibilitando a criação de um ambiente de reflexão das práticas realizadas no contexto do trabalho, saindo da gestão central, em busca de espaços entre os trabalhadores, com ampliação da capacidade de aprendizagem dos profissionais, gestores e controle social (CECCIM RB, 2005). 
Sampaio GB, et al. (2019) cita as Diretrizes Curriculares Nacionais como norteadora da formação profissional no que tange à Educação Permanente. Os autores reiteram que é necessário favorecer a possibilidade de diálogos formativos para implementação de relações transversais entre os profissionais, pacientes e toda esfera de gestão.

Considerando este cenário, de possibilidades e desafios, buscou-se, como objetivo de pesquisa, conhecer as percepções da gestão em relação à Educação Permanente em Saúde e identificar o conhecimento dos profissionais da Atenção Primária à Saúde sobre a Política Nacional de Educação Permanente em Saúde e traz em si a justificativa de reflexão sobre o assunto, com possibilidade de promover a sensibilização da gestão acerca da temática.

\section{MÉTODOS}

Este estudo tem como característica ser do tipo exploratório descritivo, com abordagem mista sequencial. A abordagem mista toma como referencial teórico os apontamentos de Creswell JW (2010).

Foram formados dois grupos, dos quais o primeiro grupo foi composto pelos gestores de saúde do município, que incluiu o Secretário Municipal de Saúde e a Coordenadora da Atenção Primária à Saúde, abordados para responderem a uma entrevista semiestruturada.

O segundo grupo inseriu os profissionais da Atenção Primária à Saúde, que foram convidados a responder um questionário, composto por dezoito questões, utilizando a escala de Likert, que abordava o conhecimento prévio sobre a Política Nacional de Educação Permanente em Saúde e a Educação Permanente em Saúde no contexto de suas equipes de trabalho, bem como a importância da implementação de um programa de Educação Permanente em Saúde para ampliação do conhecimento dos profissionais de saúde. A Atenção Primária do município é composta por 10 equipes de Estratégia Saúde da Família, e uma equipe de Núcleo Ampliado de Saúde da Família e Atenção Básica (NASF AB), um universo de 74 pessoas, que responderam o questionário.

Esta pesquisa foi aprovada pelo Comitê de Ética em Pesquisa sob o parecer n 2.614 .563$.

\section{RESULTADOS E DISCUSSÃO}

Da análise das entrevistas com os gestores do município, Secretário Municipal de Saúde e Coordenadora da Atenção Primária à Saúde, utilizando-se os preceitos de Bardin L (2011) emergiram dos discursos as seguintes categorias: "Importância da EPS"; "Necessidade de implantação de um Programa de EPS"; "Criação de um Núcleo de EPS"; "Melhoria da Atenção à Saúde pela EPS".

\section{A importância da EPS}

Durante a entrevista os gestores foram questionados sobre a importância de ter um programa institucional de EPS para Atenção Primária à Saúde, e a transformação das práticas profissionais foi uma das preocupações dos gestores, relatando que:

A educação permanente deve servir para preencher lacunas e transformar as práticas profissionais e a própria organização do trabalho. (Gestor M)

A PNEPS institui que a EPS busca a transformação das práticas, pela reflexão do cotidiano, onde cada membro da equipe é importante para construção de saberes compartilhados, assistência centrada no usuário e cuidado integral. Busca-se um profissional crítico, diante de sua realidade, onde a EPS possa trazer debates, com construção de novo sentido, com reflexão do dia a dia de trabalho e da formação em saúde, com produção de espaços coletivos que permeiam a realidade, com apoio científico (CECCIM RB, 2005). Outros temas levantados pelos gestores foram o aumento da produtividade e o incentivo, com ações e reflexos sobre o processo de trabalho:

[...] todo servidor, em qualquer função, se ele não for incentivado né, não vai produzir mais que aquilo que está acostumado, não tiver incentivo, que é legal, bacana, que ele produza mais, que ele tenha novos conhecimentos dentro da área de atuação, que tudo muda, isso com certeza ajudaria muito, para que ele produza mais. (Gestor W). 
O interesse da gestão federal, estadual e municipal, sobre a avaliação, vem ao encontro da mensuração das atividades realizadas e as questões econômicas, configurando também um espaço de produção de aprendizado e diálogo (AKERMAN M e FURTADO JP, 2016).

O incentivo a qualificação dos profissionais pode ocorrer com a implementação da EPS, com debates entre a equipe, e reflexão sobre as dificuldades e acertos, com intuito de transformar as práticas pela problematização (BRASIL, 2004).

Em seguida, os gestores foram questionados sobre a necessidade de implementação de um programa de EPS na Atenção Primária a Saúde. Das respostas obtidas, pode-se resumir os discursos em quatro unidades de significados: motivação, necessidade de espaço físico para EPS, integração do cotidiano e desenvolvimento de competências.

Um dos gestores considera que o profissional de saúde tem um ato muito mecânico, representado pela fala:

[...] é muito mecânico, a gente tem muito servidor ai 20 anos, 15 anos, 30 anos, mas que alguns estão desmotivados, não são todos, até pela carga do dia a dia, a gente não vê nada diferente, também a rotina é a mesma, forma de cobrança, talvez não motive a fazer nada diferente [...] se a gente conseguir fazer um trabalho em EPS, eu acredito que melhore sim, porque o reflexo é direto na pessoa, tá motivado, ela vai tentar fazer um pouco mais para aquela pessoa [...] aquele paciente. (Gestor W)

A EPS é fundamental nesse processo de motivação, criando um espaço de debate do cotidiano, onde a gestão participe com melhores condições de trabalho, com compreensão dos anseios de crescimento dos profissionais, com diálogo, e também faça provimento de recursos financeiros para essas atividades (BRASIL, 2009).

O espaço físico foi considerado um determinante para um dos gestores, descrito na fala:

Penso que poderíamos ter um espaço físico. O espaço que hoje a secretaria não tem [...] espaço nosso. (Gestor W)

Um dos gestores considera importante o desenvolvimento de competências, descrito na fala a seguir:

De um modo geral, a integração do profissional ao cotidiano [...] dos serviços de saúde se desenvolve na prática de competências, habilidades e conhecimento acumulados. (Gestor M)

Os profissionais de saúde, em sua grande maioria, vêm de uma formação tradicional e fragmentada, e isso leva a profissionais especializados, com muita dificuldade de enxergar o todo, de forma sistêmica. A Atenção Primária à Saúde necessita de profissional capaz de agregar conhecimentos e núcleos de saberes, propiciando uma prática integrada as necessidades da população (CECCIM RB, 2005).

Depois de realizada a entrevista com os gestores, iniciou-se a parte quantitativa deste estudo, quando foram realizadas reuniões nas nove Unidades de Saúde do município, compostas por dez equipes de Atenção Primária à Saúde e NASF AB, onde foram esclarecidos os objetivos da pesquisa e sua à intencionalidade.

Os participantes da pesquisa foram 74 profissionais.

Cada uma das equipes da Atenção Primária à Saúde do município é composta por médico, enfermeiro, técnico em enfermagem, agentes comunitários de saúde. Algumas equipes possuem o componente da saúde bucal, composta por dentista e auxiliar de consultório odontológico.

A equipe de NASF AB é composta por médico pediatra, assistente social, psicólogo. A classe com maior número de profissionais são os agentes comunitários de saúde, devido à composição das equipes, que possuem de 4 a 5 agentes por equipe (Gráfico 1). 
Gráfico 1 - Profissionais Participantes.

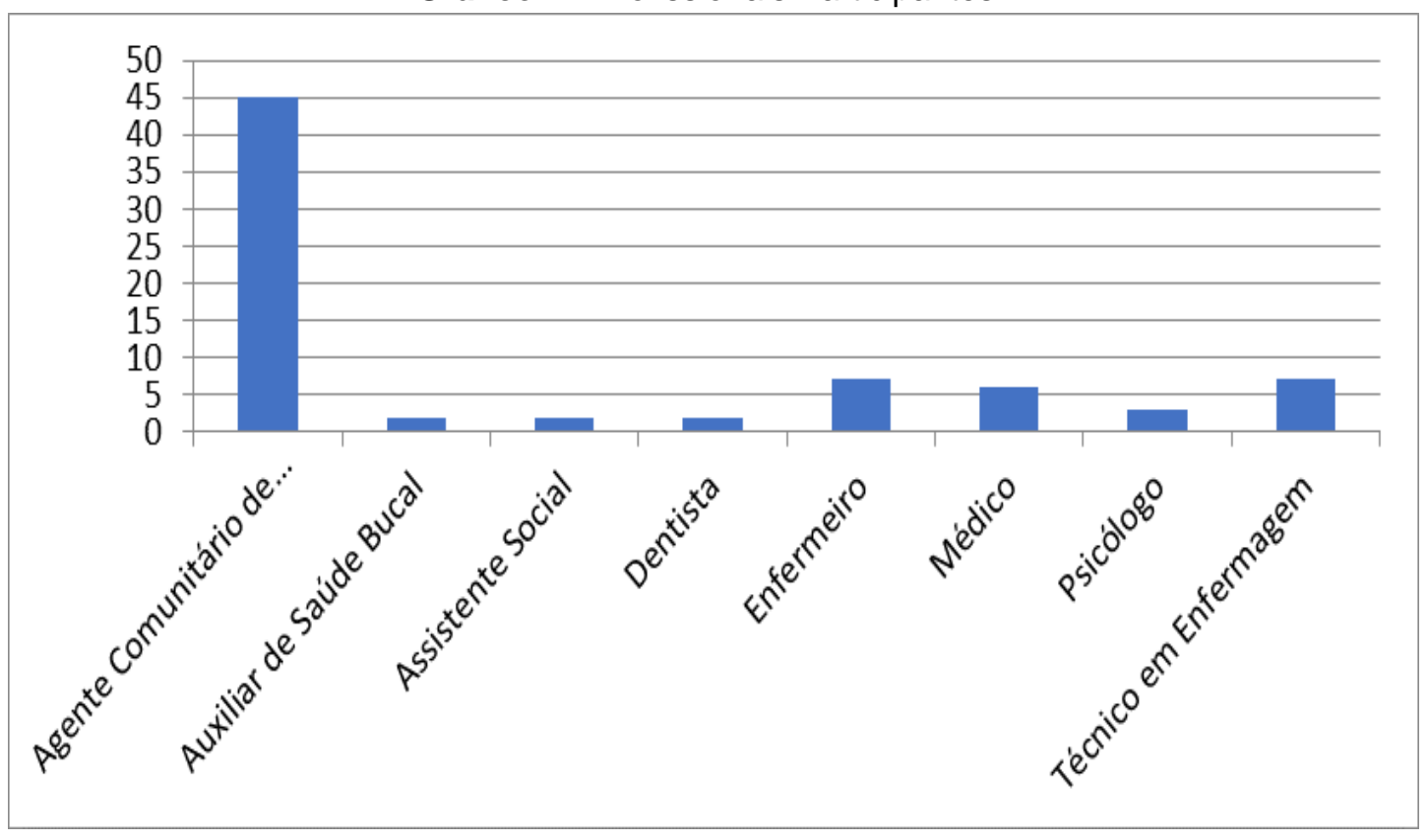

Fonte: GONÇALVES SO, et al., 2020.

Quando perguntados se tinham conhecimento sobre a PNEPS, 44 profissionais representando $59,4 \%$ relatam conhecer, enquanto 30 profissionais representando 40,54\% desconhecem (Gráfico 2).

Gráfico 2 - Conhecimento da PNEPS.

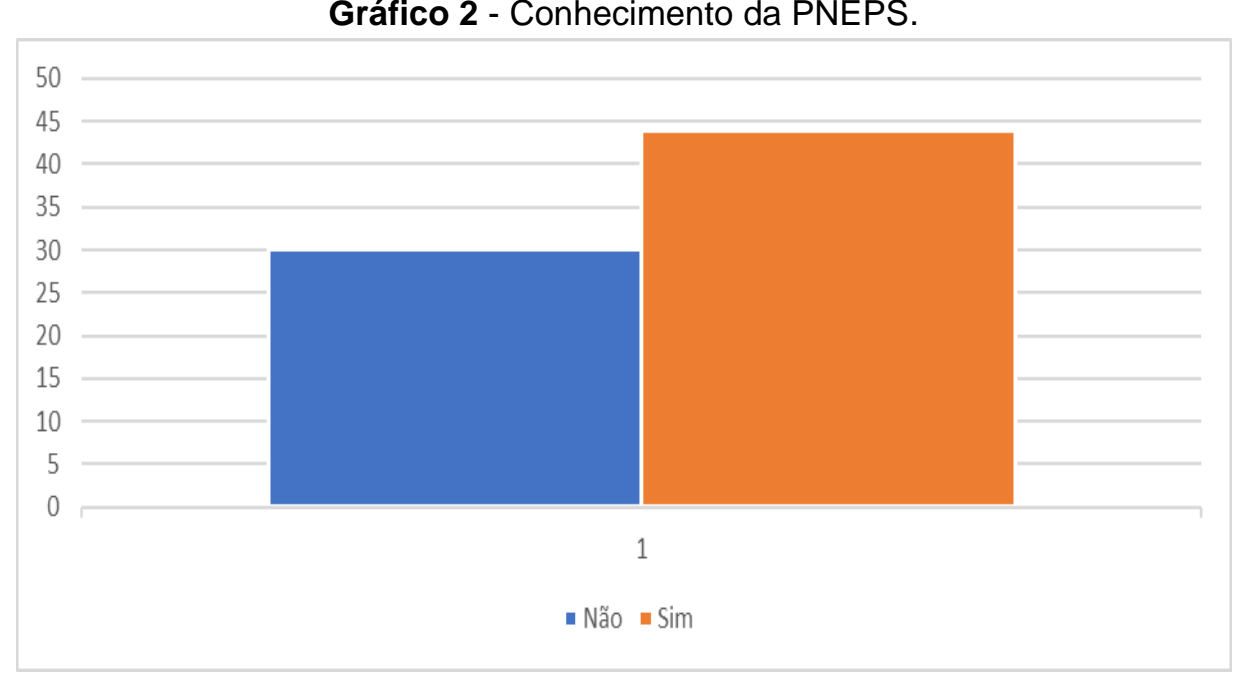

Fonte: GONÇALVES SO, et al., 2020.

Os dados demonstram que o tema ainda precisa ser discutido para que ocorra alcance de todos profissionais de saúde, pois 30 dos participantes da pesquisa relataram desconhecer a política, que representa $40,54 \%$ da amostra. É um número significativo diante do quadro de profissionais da Atenção Primária à Saúde e equipe de NASF AB do município, o que revela a importância premente de um núcleo de EPS, a fim de propiciar um programa para capacitação constante das equipes de saúde.

É de grande valia que o Ministério da Saúde esteja fomentando a EPS novamente, através de seis oficinas ocorridas em regiões do país em 2017, pois um município de pequeno porte, tem muita dificuldade em estruturar um programa de EPS, tanto do ponto de vista de recursos financeiros quanto de profissionais qualificados para a implementação (BRASIL, 2018). 
A educação, em todas as suas vertentes, é um conjunto de fatores que precisa de uma ordenação do ministério, dos estados, das secretarias municipais de saúde e fundamentalmente da disposição da equipe em fazer parte do processo de construção, muitas vezes primeiramente, uma desconstrução, para dar liberdade a um novo modelo, construído através das experiências dos integrantes do grupo, com a troca de ótica sobre todo o processo de trabalho (GIOVANELLA L, et al., 2014). Quando questionados se estariam mais qualificados se participassem de um programa de EPS, $42(56,75 \%)$ concordaram que estariam mais preparados para a prática, $29(39,18 \%)$ concordaram totalmente, $(1,35 \%)$ discordou e $2(2,70 \%)$ discordam totalmente.

Silva MIA, et al. (2019) ao relatar a experiência de implantação de planejamento estratégico, utilizou a metodologia da Roda de conversa para construir o Plano de Intervenção relacionado à Educação permanente em Saúde na ESF, aponta que o maior problema relatado foi a "baixa efetividade da política de EPS", pelo olhar dos profissionais de saúde.

Pode-se observar que concordam e concordam totalmente que estariam mais preparados para o trabalho, $71(95,96 \%)$ dos participantes da amostra, o que é um número significativo, revelando, portanto, que os profissionais consideram importante a EPS na qualificação profissional, apesar de diferente a intensidade, ambos grupos concordam que estariam mais preparados com atividades da EPS. Apenas três discordaram, sendo que dois discordaram totalmente e um discordou, sendo um número reduzido diante da amostra de profissionais (Gráfico 3).

Gráfico 3 - Qualificação dos profissionais com EPS.

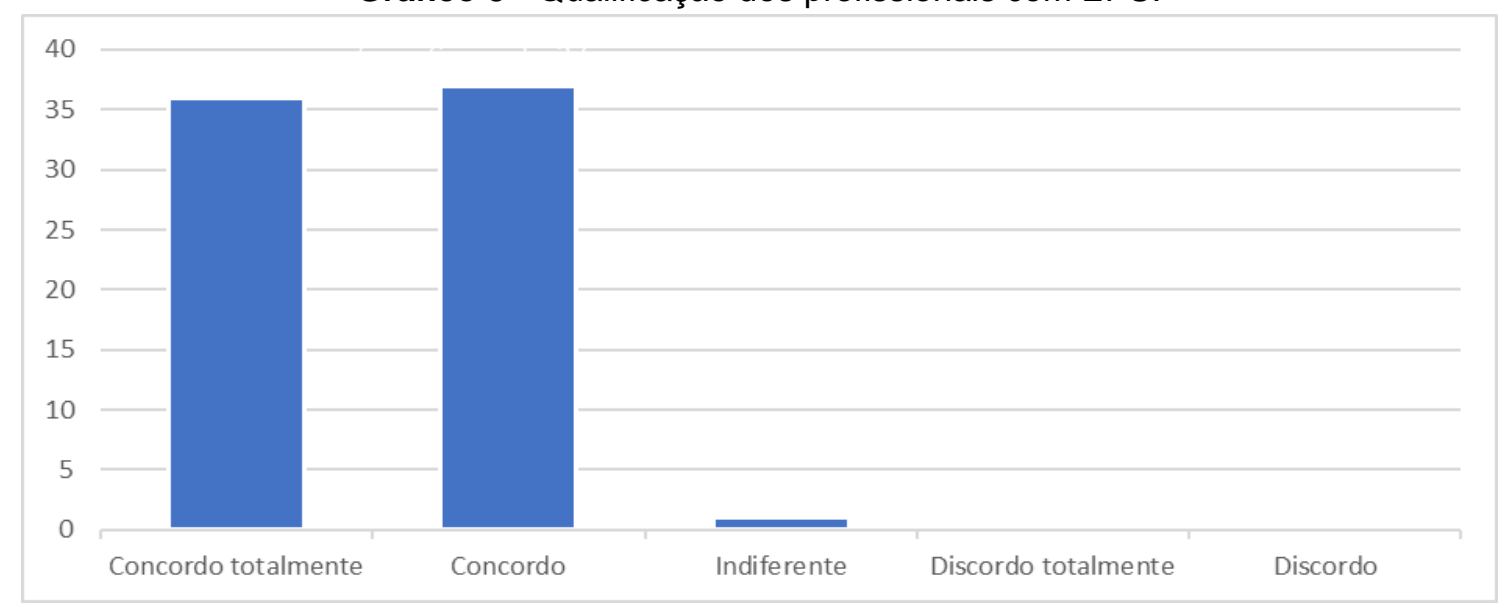

Fonte: GONÇALVES SO, et al., 2020.

A implementação de um programa de EPS traria benefícios para a equipe de saúde e NASF AB propiciando discussão entre o grupo de trabalho, podendo contar com o apoio matricial da equipe NASF AB. Assim, importante destacar que, para tanto, faz-se necessário um despertar dos profissionais e principalmente da gestão, que conduza a estruturação de um programa que possibilite a capacitação do grupo de trabalho.

A EPS traz o protagonismo da equipe diante de seu usuário, a fim de propiciar melhor qualidade de assistência. Esta qualidade, tão almejada, quer pelos usuários, quer pelos profissionais, deve ser avaliada com a intencionalidade de conhecer se os objetivos foram atingidos, dessa maneira, orientando o processo de construção do conhecimento.

Além da implementação da EPS, é importante a avaliação de todas as ações desenvolvidas, a fim de nortear o processo, conhecer o que está dando certo e aquilo que precisa ser melhorado. A avaliação é imprescindível para a análise dos dados, em todas as etapas da pesquisa, oferendo instrumentos para a tomada de decisão, com utilização de normas e critérios definidos, aplicando-se em avaliação normativa e pesquisa avaliativa. (HARTZ ZMA, et al., 1997)

A EPS é discutida desde 2004, passou por diversos momentos, mas sua implementação depende de muitos fatores, como a presença de uma instituição de ensino capaz de fomentar o processo, trabalhadores 
e gestores abertos à discussão e apropriação de saberes e fazeres. A participação da equipe multiprofissional, e recursos financeiros para realização das atividades de EPS, com organização dos municípios para que possam ser capazes de reconhecer seu território, os dados epidemiológicos desse território, e por fim condições técnicas/científicas de avaliar seus objetivos propiciaria uma crítica construtiva sobre o processo de trabalho.

O Programa de Melhoria do Acesso à Qualidade (PMAQ) é uma ferramenta para construção de uma nova realidade sobre o processo de trabalho, compartilhando as discussões com a equipe, aproximando a gestão da realidade de cada território, e do olhar da equipe multiprofissional. O programa instituído pela Portaria 1654, de 19 de julho de 2011 e direcionado nesse primeiro momento às equipes de atenção básica, com regulamentado recurso financeiro atrelado ao componente de qualidade do piso variável da atenção básica, (BRASIL, 2011) vem ao encontro dos dados desta pesquisa, que consideram que estariam mais preparados para ofertar atenção à saúde qualificada se participassem de programas de educação permanente em saúde.

Nessa questão seguinte, foram questionados se seria possível a implantação de ações de EPS em sua unidade de saúde, e $42(31,08 \%)$ concordaram, 29 (21,46\%) concordaram totalmente, 1 (0,74\%) discordou e $2(1,48 \%)$ discordaram totalmente (Gráfico 4$)$.

Gráfico 4 - Implantação de Ações de EPS na Unidade de Saúde.

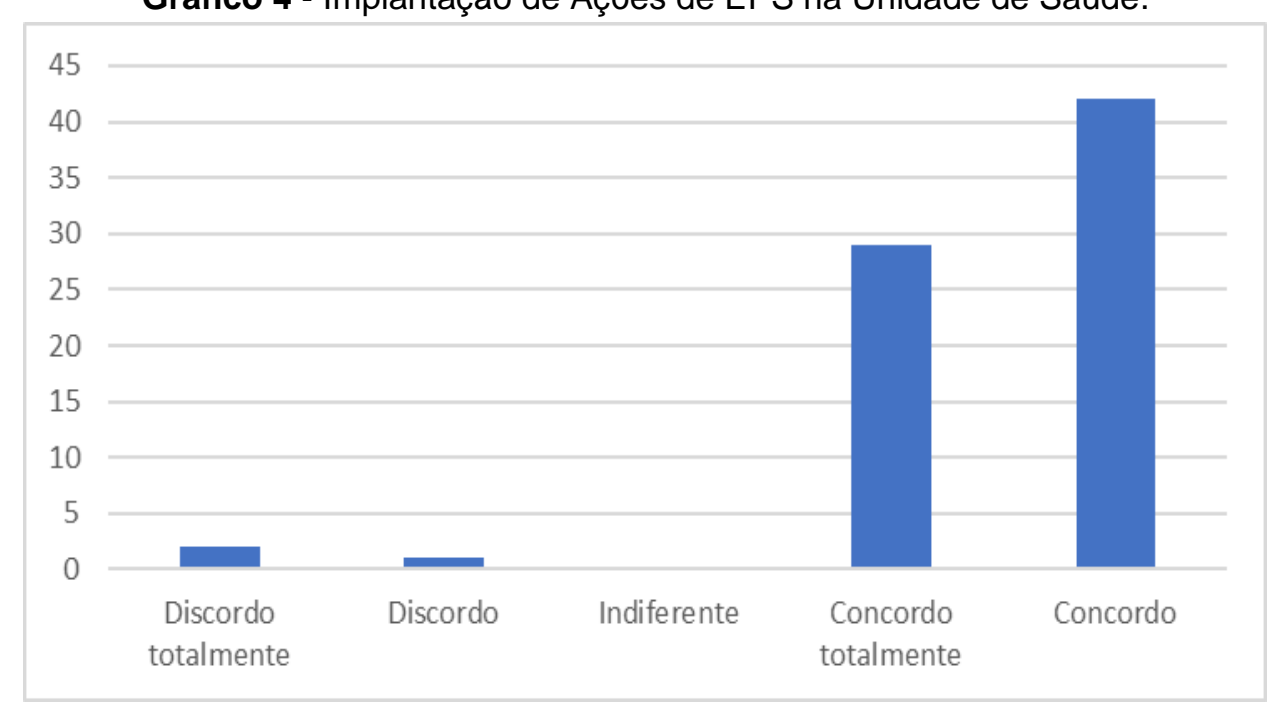

Fonte: GONÇALVES SO, et al., 2020.

Dos entrevistados na pesquisa 42 concordaram e 29 concordaram totalmente, perfazendo 71 dos entrevistados, com a indicação que seria possível a implantação de ações de EPS em sua unidade. Em detrimento de 1 participante que discordou e 2 discordaram totalmente. Dessa maneira, veem-se perspectivas de abertura entre os profissionais para implantação da EPS, demonstrando um olhar esperançoso sobre participação dos profissionais no desenvolvimento de ações de EPS.

Identificou-se que os gestores conhecem a PNPES, e a consideram importante para o aumento da produtividade dos profissionais, ampliação das agendas, com foco no maior acesso do usuário aos serviços de saúde, e diminuição das filas, não discutindo os processos de trabalho das equipes, o acesso à informação e qualificação dos profissionais.

Pondera-se como relevante que a Secretaria de Saúde possua um espaço físico para a capacitação e desenvolvimento de atividade de educação, e a gestão considera que possuem possibilidade para isso, mas não tem funcionários suficientes para o desenvolvimento da EPS, pois o quadro de concursados é muito reduzido, e a maior parte das equipes é composta por trabalhadores contratados por tempo determinado, o que dificulta o planejamento de ações que visem à qualificação. 
Constata-se que a gestão tem a percepção de que os profissionais, após alguns anos de trabalho, demonstram comodismo, dificultando a introdução de atividades que promovam mudança da assistência.

As equipes de Atenção Primária à Saúde e NASF AB, relatam, em sua maioria, que conhecem a PNEPS, e que a consideram importante no desenvolvimento de habilidades para melhoria do trabalho. Referem que a implementação de um programa de EPS seria importante e mudaria o olhar sobre a prática, com desenvolvimento de habilidades para melhoria da qualidade do serviço prestado.

O apoio entre as equipes é de substancial relevância na construção de um panorama capaz de dar amparo às angústias de cada profissional. Com desenvolvimento do apoio matricial, sob o enfoque que toda equipe que, enquanto faz o matriciamento também é matriciada pela referência, onde se busca uma nova forma de assistência à saúde, com o território e o usuário como foco principal.

Esse movimento dos profissionais de saúde é fundamental para implantação de ações de EPS, o que demonstra abertura para mudança no processo de trabalho, pois a essência da EPS é a transformação do trabalho, pela reflexão do grupo, procurando interação entre a equipe multidisciplinar, produzindo um ambiente de coletividades (CECCIM RB, 2010).

Os dados da pesquisa demonstram que os profissionais da Atenção Primária à Saúde, consideram que seria possível a implantação de ações de EPS e demonstram que consideram que existe uma perspectiva para introdução de mudanças no processo de trabalho, embora a implantação de ações da PNEPS dependa de um esforço conjunto entre a gestão federal, gestão estadual e gestão municipal, controle social, para fomentar e ordenar o processo de EPS.

A PNEPS é de grande valia para a atenção primária, com empoderamento dos profissionais de saúde, com ampliação do escopo de atividades e qualificação da assistência à saúde, e com oportunidade de reflexão sobre o trabalho. E continuam afirmando que a importância esta centrada nos profissionais. (Ribeiro DK, et al., 2019)

\section{CONCLUSÃO}

Pela análise das entrevistas acredita-se se que o conhecimento da gestão sobre a EPS ainda é insipiente, e que necessita de ampla discussão sobre o tema para apropriação de significados e alinhamento de discursos. Faz se necessário a orientação das equipes diante das prerrogativas da PNEPS, a fim de proporcionar o desenvolvimento de ações que contemplem o aprendizado necessário e significativo, com compartilhamento de saberes entre a Atenção Primária, Estratégia Saúde da Família e NASF AB, capaz de potencializar, com amparo das metodologias ativas de aprendizagem, a construção do conhecimento no trabalho e para o trabalho.

\section{REFERÊNCIAS}

1. AKERMAN M, FURTADO JP. Práticas de avaliação em saúde no Brasil: diálogos. 1ª ed. Porto Alegre: Rede Unida, 2016; 374 p.

2. BARDIN, L. Análise de conteúdo. 1ª ed. São Paulo: Edições 70, 2011; 280p.

3. BRASIL. Lei no 8.080, de 19 de setembro de 1990. Dispõe sobre as condições para a promoção, proteção e recuperação da saúde, a organização e o funcionamento dos serviços correspondentes e dá outras providências. In: Diário Oficial da União. Brasília.

4. BRASIL. Ministério da Saúde. Portaria no 198/GM/MS, de 13 de fevereiro de 2004. Institui a Política Nacional de Educação Permanente em Saúde como estratégia do Sistema Único de Saúde para a formação e o desenvolvimento de trabalhadores para o setor e dá outras providências. In Diário Oficial da União. Brasília.

5. BRASIL. Ministério da Saúde. Secretaria de Gestão do Trabalho e da Educação na Saúde. Departamento de Gestão da Educação em Saúde. A educação permanente entra na roda: polos de educação permanente em saúde: conceitos e caminhos a percorrer. Brasília: Ministério da Saúde, 2005; 36p.

6. BRASIL. Ministério da Saúde. Secretaria de Gestão do Trabalho e da Educação na Saúde. Departamento de Gestão da Educação em Saúde. Política Nacional de Educação Permanente em Saúde. Brasília: Ministério da Saúde, 2009; $63 p$. 
7. BRASIL. Ministério da Saúde. Secretaria de Atenção à Saúde. Política Nacional de Humanização da Atenção e Gestão do SUS. Gestão participativa e cogestão / Ministério da Saúde, Secretaria de Atenção à Saúde, Política Nacional de Humanização da Atenção e Gestão do SUS. Brasília: Ministério da Saúde, 2009; 56p.

8. BRASIL. Ministério da Saúde. Portaria no 2.488, de 21 de outubro de 2011. Aprova a Política Nacional de Atenção Básica, estabelecendo a revisão de diretrizes e normas para a organização da Atenção Básica, para a Estratégia Saúde da Família (ESF) e o Programa Agentes Comunitários de Saúde (PACS). In Diário Oficial da União. Brasília.

9. BRASIL. Ministério da Saúde. Decreto no 7588, de 28 de junho de 2011 . Regulamenta a Lei $n^{\circ} 8.080$, de 19 de setembro de 1990, para dispor sobre a organização do Sistema Único de Saúde - SUS, o planejamento da saúde, a assistência à saúde e a articulação interfederativa. In Diário Oficial da União. Brasília.

10. BRASIL. Ministério da Saúde. Secretaria de Gestão do Trabalho e da Educação na Saúde. Manual Técnico 2018 Programa para o Fortalecimento das Práticas de Educação Permanente em Saúde no SUS - PRO EPS-SUS / Ministério da Saúde, Secretaria de Gestão do Trabalho e da Educação na Saúde. Brasília: Ministério da Saúde, 2018; $44 p$.

11. CECCIM RB. Educação dos profissionais de saúde e compromissos públicos com a integralidade: as disposições do aprender SUS. In: PINHEIRO R; SILVA-JUNIOR AG (Org). Por uma sociedade cuidadora. 1르. ed. Rio de Janeiro: Abrasco, 2010; 523p.

12. CECCIM RB. Educação Permanente em Saúde: desafio ambicioso e necessário. Interface: Comunicação, Saúde, Educação, 2005; 9(16): 161-168.

13. CECCIM RB, FEUERWERKER LCM. O Quadrilátero da Formação para Área da Saúde: Ensino, Gestão, Atenção e Controle Social. Phisis: Rev Saúde Coletiva, 2004; 14(1): 41-65.

14. CRESWELL JW. Projeto de Pesquisa: Métodos Qualitativo, Quantitativo e Misto. 3ª ed. Porto Alegre: Artmed, 2010; 296p.

15. DAVINI MC. Enfoques, Problemas e Perspectivas na Educação Permanente dos Recursos humanos de Saúde. Política Nacional de Educação Permanente em Saúde. Série pacto pela saúde, volume 9. Brasília: Ministério da Saúde, 2009; 63p.

16. GIOVANELA L, et al. Políticas e Sistema de Saúde no Brasil. 2ª ed. Rio de Janeiro: Editora Fiocruz, 2014; 1100p.

17. HARTZ ZMA (Org). Avaliação em Saúde: dos modelos conceituais à prática na análise da implantação de programas. Rio de Janeiro: Editora Fiocruz, 1997; 132p.

18. RIBEIRO DK, et al. Educação Permanente em Saúde: relato de experiência do desenvolvimento de questionário avaliativo online. Revista Eletrônica Acervo Saúde, 2019; 11(18): e1644.

19. SAMPAIO GB, et al. Educação Permanente e o Processo Formativo dos Profissionais da Saúde: Entrelace de Saberes. Revista Eletrônica Acervo Saúde, 2019; 25: e630.

20. SILVA MIA, et al. Educação Permanente em Saúde na Estratégia de Saúde da Família: Relato da Elaboração do Plano de Intervenção. Revista Eletrônica Acervo Saúde, 2019; 11(16): e1527. 